\title{
ESPÉCIES DE COBERTURA DE INVERNO E NITROGÊNIO NA CULTURA DO MILHO EM SISTEMA DE PLANTIO DIRETO
}

\section{WINTER COVER CROPSAND NITROGEN TO CORN IN NO-TILLAGE SYSTEM}

\author{
Igor Quirrenbach de CARVALHO \\ Mauro José Stegg da SILVA² \\ Amir PISSAIA ${ }^{3}$ \\ Volnei PAULETTI ${ }^{4}$ \\ João Carlos POSSAMA| ${ }^{5}$
}

\begin{abstract}
RESUMO
Na região sul do Brasil, com o aumento da produção de milho no sistema de plantio direto (SPD), estão sendo introduzidas algumas espécies vegetais de inverno para cobertura de solo, que beneficiem tanto o milho cultivado em sucessão, como o próprio SPD. O objetivo deste trabalho foi avaliar o efeito de espécies para cobertura de inverno (aveia preta, nabo forrageiro, ervilhaca comum e azevém) e quatro tipos de combinações (aveia+ervilhaca, aveia+nabo, ervilhaca+nabo e aveia+ervilhaca+nabo), sobre o desempenho do milho cultivado em SPD, na presença e ausência de adubação nitrogenada em pós-emergência no milho. $O$ experimento foi realizado em um Gleissolo Melânico na Fazenda do Pulo, município de Castro-PR, no ano agrícola de 2001/2002. A produção de massa seca das coberturas foi maior com a presença de aveia preta. Independente da espécie de cobertura de inverno, a aplicação de $\mathrm{N}$ em pós-emergência no milho proporcionou aumento na altura de plantas, altura de inserção de espigas, diâmetro do colmo, número de espigas, número de espigas por planta, massa de grãos por espiga, massa de mil grãos e produtividade de grãos de milho. A cobertura aveia preta + nabo forrageiro proporcionou maior produtividade de grãos de milho que a cobertura com a ervilhaca solteira.
\end{abstract}

Palavras-chave : plantas de cobertura, rotação de culturas, matéria seca, manejo do solo

\begin{abstract}
In the southern of Brazil, with the increase of corn production in no-tillage system, some winter cover crops are being evaluated, the purpose is to obtain a soil cover that benefit not only the corn cultivated but also the no-tillage. The objective of this work was to evaluate the effects of four winter cover crops (black oat, forage turnip, common vetch and ryegrass) and four combinations (oat + vetch, oat + turnip, vetch + turnip and oat + vetch + turnip) with and without nitrogen fertilizer in post-emergency applied in the corn ( 0 and $\left.108 \mathrm{~kg} \mathrm{ha}^{-1}\right)$. The experiment was carried in Castro, Paraná state, in a Melanic Gleysoil, in the agricultural year of 2001/ 2002. Dry matter cover crops were increased with black oat presence. Independent of cover crops, the post-emergency nitrogen in corn provided increase on plant height, ear height, stem diameter, number of ear per plant, mass of grains per ear, mass of thousand grains and corn grain yield. The combination black oat and turnip resulted in a larger corn grain yield than the single vetch.

Key-words : winter cover crops, crop rotation, dry matter, soil management.
\end{abstract}

\footnotetext{
'Engenheiro Agrônomo, Pesquisador, Fundação ABC, PR 151, km 288, CEP 84166-990, Castro - PR. E-mail: igor@fundacaoabc.org.br;

2 Engenheiro Agrônomo, Pinhais - PR;

${ }^{3}$ Engenheiro Agrônomo, Doutor, Professor do Departamento de Fitotecnia e Fitossanitarismo do SCA/UFPR;

${ }^{4}$ Engenheiro Agrônomo, Mestre, Pesquisador da Fundação ABC;

${ }^{5}$ Engenheiro Agrônomo, Mestre, Professor do Departamento de Fitotecnia e Fitossanitarismo do SCA/UFPR.
} 


\section{INTRODUÇÃO}

Na região sul do Brasil, muitas áreas são cultivadas intensivamente, sem manejo adequado, provocando redução no teor de matéria orgânica dos solos, e desta forma, favorecendo o processo erosivo. $\mathrm{O} N$ é o nutriente mais afetado por esse processo, provocando sérias limitações na produtividade das culturas. Isto ocorre, porque a principal fonte desse nutriente é a matéria orgânica, que se encontra na camada superficial do solo e sofre perda seletiva durante a erosão hídrica (DA ROS, 1993).

No Paraná, mais especificamente, na região dos Campos Gerais, problemas referentes à conservação do solo vêm sendo minimizados através do emprego do sistema de plantio direto (SPD). Um dos fatores imprescindíveis para o sucesso deste sistema é a presença de cobertura vegetal morta sobre o solo, já que os restos culturais têm importante papel na redução das perdas de solo e água e ainda na diminuição da temperatura do solo durante o verão (BRAGAGNOLO e MIELNICZUK, 1990; DEBARBA e AMADO, 1997; DERPSCH et al., 1985; ROMAN e DIDONET, 1990). A utilização de plantas de cobertura durante o período de entressafra proporciona melhoria da capacidade produtiva do solo, favorece sua estruturação e fornece nutrientes à sua sucessão (WILDNER e DADALTO, 1992), além de contribuir para o controle de plantas invasoras pelo efeito supressor/alelopático e promover a manutenção ou até mesmo o aumento nos teores de matéria orgânica do solo (CALEGARI et al., 1993). Tanto o nabo forrageiro quanto as leguminosas em cultivo solteiro ou em consórcio com gramíneas, resultam em maior fornecimento de $\mathrm{N}$ para as culturas subseqüentes como o milho, diminuindo a necessidade de aplicação de $\mathrm{N}$ mineral (AMADO et al., 2002).
Este trabalho teve como objetivo avaliar o efeito de espécies para cobertura de inverno, aveia preta (Avena strigosa), nabo forrageiro (Raphanus sativus), ervilhaca comum (Vicia sativa) e azevém (Lolium multiflorum), e quatro tipos de combinações (aveia+ervilhaca, aveia+nabo, ervilhaca+nabo e aveia+ervilhaca+nabo), sobre a produtividade do milho e seus componentes, cultivado em SPD, na presença e ausência de adubação nitrogenada em pós-emergência.

\section{METODOLOGIA}

O experimento foi realizado em lavoura comercial de milho, na Fazenda do Pulo, município de Castro-PR, primeiro planalto paranaense, latitude 244' $30^{\prime \prime} \mathrm{S}$, longitude 500' $54^{\prime \prime} \mathrm{W}$, durante o ano agrícola 2001/2002, em um Gleissolo Melânico Distrófico típico (EMBRAPA, 2002). Os atributos químicos e granulométricos das camadas superficiais do solo são apresentados na Tabela 1. O local apresenta altitude de $970 \mathrm{~m}$ acima do nível do mar, sendo predominante o clima subtropical úmido, Cfb de Köppen (IAPAR, 2005). A precipitação pluviométrica ocorrida durante o desenvolvimento das culturas de cobertura foi de $411 \mathrm{~mm}$, e durante 0 desenvolvimento do milho foi de $803 \mathrm{~mm}$, de acordo com dados da estação agrometeorológica da Fundação $A B C$, posicionada no município de Castro - PR, aproximadamente a $10 \mathrm{~km}$ do local do ensaio. Houve distribuição regular das chuvas, com exceção do início de desenvolvimento da cultura do milho, entre os dias $23 / 10 / 2001$ e $10 / 11 / 2001$, quando as precipitações pluviométricas foram de apenas 4,2 $\mathrm{mm}$.

TABELA 1 - Análise química e física do solo da área experimental. Fazenda do Pulo, Castro-PR, 2001.

\begin{tabular}{|c|c|c|c|c|c|c|c|c|c|c|c|c|c|}
\hline $\begin{array}{l}\text { Prof. } \\
(\mathrm{cm})\end{array}$ & $\begin{array}{l}\text { P resina } \\
\left(\mathrm{mg} \mathrm{dm}^{-3}\right)\end{array}$ & $\begin{array}{c}\text { M.O.* } \\
\left(\mathrm{g} \mathrm{dm}^{-3}\right)\end{array}$ & $\begin{array}{c}\mathrm{pH} \\
\left(\mathrm{CaCl}_{2}\right)\end{array}$ & $\mathrm{H}+\mathrm{Al}$ & Al & $\begin{array}{c}\mathrm{K} \\
\text { (mmo }\end{array}$ & $\begin{array}{l}\mathrm{Ca} \\
\mathrm{l}_{\mathrm{c}} \mathrm{dm}^{-}\end{array}$ & $\begin{array}{l}\mathrm{Mg} \\
3 \text { ) } \\
----\end{array}$ & CTC* $^{*}$ & $\begin{array}{l}\mathrm{V}^{*} \\
--\end{array}$ & $\begin{array}{l}\text { Al\%* } \\
\%) ~--\end{array}$ & $\begin{array}{r}\text { Argila } \\
--(g\end{array}$ & $\begin{array}{l}\text { Areia } \\
\left.g^{-1}\right)--\end{array}$ \\
\hline $0-10$ & 31 & 50 & 4,6 & 98 & 14 & 3,3 & 30 & 15 & 146 & 33 & 23 & 333 & 509 \\
\hline $10-20$ & 13 & 39 & 4,3 & 121 & 28 & 2,1 & 21 & 14 & 158 & 23 & 43 & 336 & 526 \\
\hline
\end{tabular}

*M.O.= matéria orgânica, CTC= capacidade de troca catiônica, $V=$ saturação por bases, $A 1 \%=$ saturação por alumínio.

Anteriormente à instalação do experimento, a área foi cultivada por dois anos com a seqüência aveia preta + azevém e soja, com aplicação de adubo mineral apenas na cultura de verão, e pastejo direto com bovinos de corte das gramíneas no inverno.

O delineamento experimental empregado foi o de blocos ao acaso, em parcelas subdivididas, com quatro repetições. Os tratamentos consistiram de uma combinação de oito coberturas de solo, constituídas de quatro espécies mais quatro combinações (Tabela 2), com duas doses de $\mathrm{N}$ em pós-emergência no milho (0 e $\left.108 \mathrm{~kg} \mathrm{ha}^{-1}\right)$, totalizando 16 tratamentos. Nas parcelas principais de $10 \times 5 \mathrm{~m}$, foram utilizadas as coberturas, enquanto que nas sub-parcelas de $5 \times 5 \mathrm{~m}$, foram utilizadas as doses de $\mathrm{N}$ no milho. A área útil compreendeu as três linhas centrais, com $3,0 \mathrm{~m}$ de comprimento cada, desprezando-se 1,0 $\mathrm{m}$ nas extremidades como bordadura, totalizando $8,1 \mathrm{~m}^{2}$. 
QUIRRENBACH, I. et al. Espécies de cobertura...

TABELA 2 - Espécies de cobertura e combinações entre as espécies, e respectivas quantidades de sementes utilizadas.

\begin{tabular}{cc}
\hline Espécies de Cobertura & Sementes $\left(\mathrm{kg} \mathrm{ha}^{-1}\right)$ \\
\hline Aveia Preta & 60 \\
Azevém & 40 \\
Ervilhaca Comum & 40 \\
Nabo Forrageiro & 20 \\
Aveia + Ervilhaca & $40+30$ \\
Aveia + Nabo & $40+15$ \\
Ervilhaca + Nabo & $30+15$ \\
Aveia + Ervilhaca + Nabo & $30+20+10$ \\
\hline
\end{tabular}

Antes da instalação do experimento, o solo foi preparado com uma gradagem leve. As espécies de inverno foram semeadas a lanço em 19/05/2001, sem adubação, utilizando-se a quantidade de sementes descrita na Tabela 2. Para a incorporação das sementes foi realizada uma gradagem leve. No dia 07/06/2001 foi aplicado a lanço $2,0 \mathrm{t} \mathrm{ha}^{-1} \mathrm{de}$ calcário dolomítico (PRNT 71\%), em superfície, sobre as coberturas, segundo recomendação de SÁ (1995a). O manejo das espécies foi realizado dia 03/ 09/2001, 107 dias após a semeadura, por meio da aplicação de herbicida à base de glifosato na dose de $0,6 \mathrm{~kg} \mathrm{ha}^{-1}$ de i.a.

A semeadura do milho híbrido P32R21 foi realizada no dia 03/10/2001, diretamente sobre os resíduos culturais das plantas de cobertura de inverno, 30 dias após o manejo químico destas, através de semeadora equipada com mecanismo sulcador tipo haste, para a distribuição do adubo, e disco defasado para distribuição das sementes. Foi utilizado o espaçamento de $0,90 \mathrm{~m}$ entre linhas com 5,7 sementes por metro linear.

$\mathrm{Na}$ semeadura do milho, a adubação foi uniforme para todos os tratamentos, utilizando-se 28 $\mathrm{kg} \mathrm{ha}^{-1}$ de N, $98 \mathrm{~kg} \mathrm{ha}^{-1}$ de $\mathrm{P}_{2} \mathrm{O}_{5}, 56 \mathrm{~kg} \mathrm{ha}^{-1}$ de $\mathrm{K}_{2} \mathrm{O}$ e $1,0 \mathrm{~kg} \mathrm{ha}^{-1}$ de $\mathrm{Zn}$. A adubação em pós-emergência no milho foi realizada a lanço no estádio $\mathrm{V} 4,40$ dias após a semeadura, aplicando-se $60 \mathrm{~kg} \mathrm{ha}^{-1}$ de cloreto de potássio ( $36 \mathrm{~kg} \mathrm{ha}^{-1}$ de $\mathrm{K}_{2} \mathrm{O}$ ) em todas as subparcelas e $240 \mathrm{~kg} \mathrm{ha}^{-1}$ de uréia (108 $\mathrm{kg} \mathrm{ha}^{-1}$ de $\mathrm{N}$ ) apenas nas sub-parcelas com aplicação de $\mathrm{N}$ em pósemergência. Os tratos culturais como controle de plantas daninhas e de insetos, seguiram as recomendações regionais, sugeridas pela Fundação $\mathrm{ABC}$.

Para avaliação da produção de massa seca das espécies de cobertura de inverno e das combinações, coletaram-se amostras após a semeadura do milho, numa área de $0,25 \mathrm{~m}^{2}$ por parcela, que foram secas em estufa a $65^{\circ} \mathrm{C}$, até peso constante. Antes da colheita do milho foi determinada, em 10 plantas por parcela, a altura de planta e de inserção da espiga, pela medição da distância entre o nível do solo e a inserção da folha bandeira e da espiga principal, respectivamente, e o diâmetro do colmo no segundo entrenó, acima do solo. Também foi contado o número de plantas e de espigas na área útil. Após a colheita e processamento do material, determinaram-se a produtividade e a massa de mil grãos, ajustadas a $13 \%$ de umidade. O número de espigas por planta e a massa de grãos por espiga foram calculados.

A análise estatística dos resultados constou das análises de variância, comparando-se as médias pelo teste de Tukey a $5 \%$, quando necessário.

\section{RESULTADOS E DISCUSSÃO}

Houve diferença na produção de massa seca entre as espécies de cobertura e combinações avaliadas. Os tratamentos nos quais a aveia preta esteve presente apresentaram produção significativamente maior do que os tratamentos sem a presença desta espécie (Tabela 3 ). A aveia preta solteira produziu $4.632 \mathrm{~kg} \mathrm{ha}^{-1}$ de massa seca, valor próximo aos resultados de $4.417 \mathrm{~kg} \mathrm{ha}^{-1}$, obtidos por AITA et al. (2001), $5.710 \mathrm{~kg} \mathrm{ha}^{-1}$ por PAVINATO et al. (1994), $4.150 \mathrm{~kg} \mathrm{ha}^{-1}$ por CALEGARI (1987), 4.910 $\mathrm{kg} \mathrm{ha}^{-1}$ por HEINRICHS et al. (2001) e $5.200 \mathrm{~kg} \mathrm{ha}^{-1}$ por VALENTINI (1999). Esta produção de biomassa da aveia pode ser importante para o SPD pela redução da erosão (DEBARBA e AMADO, 1997) e da incidência de plantas daninhas (PAVINATO et al., 1994), em função da presença da palha na superfície. $O$ azevém produziu menos massa seca que a aveia preta, mesmo sendo uma gramínea (Tabela 3). A produção do azevém obtida é superior aos $1.400 \mathrm{~kg}$ ha $^{-1}$, apresentados por VALENTINI (1999), que também não adubou a cultura. O azevém, no entanto, pode ter produtividades acima de $6.000 \mathrm{~kg} \mathrm{ha}^{-1}$ quando adubado (SILVA, 2005). 
QUIRRENBACH, I. et al. Espécies de cobertura...

TABELA 3 - Produção de massa seca (MS) de quatro coberturas de solo e quatro combinações. Fazenda do Pulo, Castro-PR, 2001.

\begin{tabular}{ccccccccc}
\hline & \multicolumn{8}{c}{ Espécies de cobertura e combinações } \\
\cline { 2 - 8 } & $A v^{*}$ & $A z$ & $E r$ & $N a$ & $A p+E r$ & $A p+N a$ & $E r+N a$ & $A v+E r+N a$ \\
$M S\left(\mathrm{~kg} \mathrm{ha}^{-1}\right)$ & $4632 \mathrm{a}^{* *}$ & $3045 \mathrm{bc}$ & $2839 \mathrm{c}$ & $2468 \mathrm{c}$ & $4564 \mathrm{a}$ & $3720 \mathrm{abc}$ & $2850 \mathrm{c}$ & $4340 \mathrm{ab}$ \\
\hline
\end{tabular}

${ }^{*} \mathrm{Av}$ = aveia preta, $\mathrm{Az}=$ azevém, $\mathrm{Er}$ = ervilhaca, $\mathrm{Na}=$ nabo forrageiro;

** Médias seguidas da mesma letra não diferem entre si pelo teste de Tukey a $5 \%$.

A ervilhaca com $2.839 \mathrm{~kg} \mathrm{ha}^{-1}$ de massa seca e o nabo forrageiro com $2.468 \mathrm{~kg} \mathrm{ha}^{-1}$, em cultivos solteiros, foram as coberturas com menor produção de massa seca. Para a ervilhaca, a produção obtida foi semelhante aos 2.627 e $2.316 \mathrm{~kg} \mathrm{ha}^{-1}$ de DAROS e AITA (1996), $3.322 \mathrm{~kg} \mathrm{ha}^{-1}$ de CALEGARI (1987), e $2.730 \mathrm{~kg} \mathrm{ha}^{-1}$ de HEINRICHS et al. (2001) e inferiores aos $4178 \mathrm{~kg} \mathrm{ha}^{-1}$ apresentados por FONTOURA (2005). Para o nabo forrageiro, o valor obtido foi inferior aos $5.400 \mathrm{~kg} \mathrm{ha}^{-1}$ obtidos por VALENTINI (1999) e aos $4.408 \mathrm{~kg} \mathrm{ha}^{-1}$ obtidos por FONTOURA (2005). Nos trabalhos de VALENTINI (1999) e FONTOURA (2005), não foram observadas limitações químicas no solo. Já no presente trabalho, na camada de $0-10 \mathrm{~cm}$ o teor de $P$ foi médio e a saturação por bases baixa (RAlJ et al., 1996), enquanto que a saturação por alumínio foi de 23 e $43 \%$ nas camadas de $0-10$ e $10-20 \mathrm{~cm}$, respectivamente (Tabela 1 ), o que pode ter limitado o potencial produtivo destas culturas.

Não houve interação entre os tipos de cobertura do solo e adubação nitrogenada em pósemergência no milho, para todas as variáveis avaliadas nesta cultura. Estes resultados discordam dos obtidos por DA ROS e AITA (1996) e AITA et al. (2001) que não observaram efeito da aplicação de $N$ sobre a produtividade de milho cultivado após ervilhaca, porém as produtividades foram baixas (inferioresa 5000 $\mathrm{kgha}^{-1}$ ). BORTOLINI et al. (2000), em solo com teor de matéria orgânica de $26 \mathrm{~g} \mathrm{~kg}^{-1}$, observaram que a aplicação de $\mathrm{N}$ aumentou a produtividade de milho mesmo em cultivo após ervilhaca, porém sugerem redução da dose em relação ao cultivado após aveia preta, o que concorda com SÁ (1995b), AMADO et al. (2002) e FONTOURA (2005). A ausência de interação entre tipos de cobertura e adubação nitrogenada obtida no atual trabalho, pode ser atribuída ao alto teor de matéria orgânica (Tabela 1), à baixa produção de fitomassa pela ervilhaca e a aplicação de $30 \mathrm{~kg}^{\mathrm{de}} \mathrm{N} \mathrm{ha}^{-1}$ na semeadura do milho, que segundo SÁ (1995b), pode ser responsável por 42 a $88 \%$ do ganho de produtividade com a adubação nitrogenada.

Em todas as variáveis analisadas, com exceção do número de plantas, os maiores valores foram obtidos com a aplicação de N (Tabela 4), evidenciando a importância da adição deste nutriente para a cultura do milho.

TABELA 4 - Valores de altura de planta, altura de inserção de espiga, diâmetro de colmo, população final de plantas, número de espigas por planta, massa de grãos por espiga, massa de mil grãos e produtividade de grãos de milho, em função da presença (com) ou ausência (sem) do nitrogênio em pós-emergência. Fazenda do Pulo, Castro-PR, 2002.

\begin{tabular}{llcc}
\hline Variáveis & \multicolumn{2}{c}{ Nitrogênio em pós- emergência } & \\
\cline { 2 - 3 } & Com & Sem & P-valor \\
Altura de Planta $(\mathrm{cm})$ & 291,6 & 278,7 & $<0,0001$ \\
Altura de inserção de espiga $(\mathrm{cm})$ & 109,3 & 103,2 & $<0,0001$ \\
Diâmetro de colmo (mm) & 20,75 & 19,75 & 0,0004 \\
População final de plantas (planta ha $\left.{ }^{-1}\right)$ & 59099 & 58222 & 0,1550 \\
Número de espigas por planta & 0,998 & 0,974 & 0,0008 \\
Massa de grãos por espiga $(\mathrm{g})$ & 176,5 & 132,1 & $<0,0001$ \\
Massa de mil grãos $(\mathrm{g})$ & 361,6 & 309,6 & $<0,0001$ \\
Produtividade de grãos $\left(\mathrm{kg} \mathrm{ha}^{-1}\right)$ & 10408 & 7476 & $<0,0001$ \\
\hline
\end{tabular}


QUIRRENBACH, I. et al. Espécies de cobertura...

De maneira geral, os tratamentos nos quais a aveia preta foi combinada com outras espécies, proporcionaram maiores valores para as características de altura de planta, altura de inserção da espiga e diâmetro de colmo do milho (Tabela 5). Da mesma forma, as espécies solteiras ervilhaca comum, nabo forrageiro e azevém apresentaram os menores valores para essas características, especialmente se comparadas à combinação que inclui as três culturas. A produtividade de grãos de milho para as diferentes coberturas foi superior estatisticamente no tratamento aveia preta + nabo forrageiro em relação à ervilhaca solteira (Tabela 5). Este resultado pode ser conseqüência da menor população de plantas associada à menor massa de grãos por espiga observada neste tratamento (Tabela 5). Apesar da ausência de diferença significativa, as coberturas combinadas apresentaram maiores produtividades de milho do que as coberturas com espécies solteiras.

TABELA 5 - Valores de altura de planta (AP), altura de inserção de espiga (AIE), diâmetro de colmo (DC), população final de plantas (POP), número de espigas por planta (NEP), massa de grãos por espiga (MGE), massa de mil grãos (MMG) e produtividade de grãos (PROD) de milho, em função da cobertura do solo. Fazenda do Pulo, Castro-PR, 2002.

\begin{tabular}{|c|c|c|c|c|c|c|c|c|c|c|c|c|c|}
\hline \multirow{2}{*}{$\begin{array}{l}\text { Cobertura } \\
\mathrm{Av}^{*}\end{array}$} & \multicolumn{2}{|c|}{$\begin{array}{l}\text { AP } \\
(\mathrm{cm})\end{array}$} & $\begin{array}{l}\text { AIE } \\
(\mathrm{cm}) \\
\end{array}$ & $\begin{array}{c}\mathrm{DC} \\
(\mathrm{mm})\end{array}$ & \multicolumn{2}{|c|}{$\begin{array}{c}\text { POP } \\
(\text { pl. ha-1) }\end{array}$} & \multicolumn{2}{|c|}{$\begin{array}{c}\text { NEP } \\
\left(\text { esp. pl. }{ }^{-1}\right)\end{array}$} & \multicolumn{2}{|c|}{$\begin{array}{c}\text { MGE } \\
(\mathrm{g}) \\
\end{array}$} & \multicolumn{2}{|c|}{$\begin{array}{l}\text { MMG } \\
(\mathrm{g}) \\
\end{array}$} & \multirow{2}{*}{$\begin{array}{c}\text { PROD } \\
\left(\mathrm{kg} \mathrm{ha}^{-1}\right) \\
8495 \mathrm{ab}\end{array}$} \\
\hline & 283 & $b c^{* *}$ & 107 bc & $20,2 a b c$ & 59568 & $a b c$ & 0,990 & $a b$ & 144 & C & 328 & a & \\
\hline$A z$ & 279 & $\mathrm{~cd}$ & $98 \mathrm{de}$ & 19,2 c & 60185 & $a b$ & 0,978 & $a b$ & 149 & $b c$ & 325 & a & $8838 a b$ \\
\hline Er & 270 & $d$ & $96 \mathrm{e}$ & $19,5 \mathrm{bc}$ & 56944 & c & 0,995 & $a b$ & 146 & C & 342 & a & $8312 b$ \\
\hline $\mathrm{Na}$ & 281 & bcd & 102 cde & 19,6 bc & 57407 & c & 0,998 & a & 150 & $a b c$ & 336 & a & $8646 a b$ \\
\hline $\mathrm{A} v+\mathrm{Er}$ & 296 & a & $115 \mathrm{a}$ & $21,1 \mathrm{ab}$ & 57870 & bc & 0,969 & b & 158 & $a b c$ & 333 & a & $8882 a b$ \\
\hline $\mathrm{Av}+\mathrm{Na}$ & 293 & $a b$ & $110 a b$ & $21,0 a b$ & 59722 & $a b c$ & 0,983 & $a b$ & 167 & a & 345 & a & 9846 a \\
\hline $\mathrm{Er}+\mathrm{Na}$ & 284 & $b c$ & $105 \mathrm{bcd}$ & 20,0 abc & 60648 & a & 0,985 & $a b$ & 155 & $a b c$ & 342 & a & $9195 a b$ \\
\hline $\mathrm{Av}+\mathrm{Er}+\mathrm{Na}$ & 296 & a & $116 \mathrm{a}$ & 21,5 a & 56944 & c & 0,995 & $a b$ & 165 & $a b$ & 333 & a & $9321 a b$ \\
\hline CV \% & 2,6 & & 4,2 & 4,9 & 4,1 & & 1,7 & & 9,8 & & 5,2 & & 9,9 \\
\hline
\end{tabular}

${ }^{*} \mathrm{Av}=$ aveia preta; $\mathrm{Az}=$ azevém; $\mathrm{Er}=$ ervilhaca; $\mathrm{Na}=$ nabo forrageiro;

${ }^{* \star}$ Médias seguidas da mesma letra na coluna não diferem entre si pelo teste de Tukey a $5 \%$.

A liberação rápida do $\mathrm{N}$ da ervilhaca (AITA et al., 2001) e do nabo forrageiro (FONTOURA, 2005) associada a maior produção de massa da aveia preta (Tabela 3) proporcionando maior cobertura do solo, possivelmente justificam o maior crescimento e produtividade do milho, especialmente por ter ocorrido deficiência hídrica no início do desenvolvimento dessa cultura. A associação entre espécies de decomposição rápida de resíduos em associação com as de decomposição mais lenta também é sugerida por MONEGAT (1991).

\section{CONCLUSÕES}

1. A produção de massa seca das coberturas foi maior com a presença de aveia preta;

2. A adubação nitrogenada de pós-emergência no milho proporcionou maior altura de planta, altura de inserção da espiga, diâmetro de colmo, número de espigas por planta, massa de grãos por espiga, massa de mil grãos e produtividade de grãos, em relação à ausência de aplicação;

3. A cobertura aveia preta + nabo forrageiro proporcionou maior produtividade de grãos de milho que a cobertura com a ervilhaca solteira. 


\section{REFERÊNCIAS}

1. AITA, C.; BASSO, C. J.; CERETTA, C. A.; GONÇALVES, C. N.; DA ROS, C. O. Plantas de cobertura de solo como fonte de nitrogênio ao milho. Revista Brasileira de Ciência do Solo, Viçosa, v. 25, p. 157-165, 2001.

2. AMADO, T.J.C.; MIELNICZUK, J.; AITA, C. Recomendação de adubação nitrogenada para o milho no RS e SC adaptada ao uso de culturas de cobertura do solo, sob sistema plantio direto, Revista Brasileira de Ciência do Solo, Viçosa, v. 26, p. 241248,2002

3. BORTOLINI, C. G.; SILVA, P. R. F.; ARGENTA, G. Sistemas consorciados de aveia preta e ervilhaca comum como cobertura de solo e seus efeitos na cultura do milho em sucessão. Revista Brasileira de Ciência do Solo, Viçosa, v. 24, p. 897-903, 2000.

4. BRAGAGNOLO, N.; MIELNICZUK, J. Coberturas do solo por resíduos de oito seqüências de culturas e seu relacionamento com a temperatura e umidade do solo. Revista Brasileira de Ciência do Solo, Campinas, v. 13, p. 91-98, 1990

5. CALEGARI, A. Adubação verde e rotação de culturas no sudoeste do Paraná. In: REUNIÃO DE ROTAÇÃO DE CULTURAS, Ponta Grossa, 1987. Anais. Ponta Grossa: IAPAR, 1987. p. 1-16.

6. CALEGARI, A.; MONDARDO, A.; BULISANI, E.A.; WILDNER, L.P.; COSTA, M.B.B.; ALCÁNTARA, P.B.; MIYASAKA, S.; AMADO, T.J.C. Adubação verde no sul do Brasil. 2. ed. Rio de Janeiro: Assessoria e Serviços e Projetos em Agricultura Alternativa AS-PTA, 1993. $346 \mathrm{p}$.

7. DA ROS, C. O. Plantas de inverno para cobertura do solo e fornecimento de nitrogênio ao milho em plantio direto. Santa Maria, 1993. 85 f. Dissertação (Mestrado em Ciência do Solo) - Universidade Federal de Santa Maria.

8. DA ROS, C. O.; AITA, C. Efeito de espécies de inverno na cobertura do solo e fornecimento de nitrogênio ao milho em plantio direto. Revista Brasileira de Ciência do Solo, Campinas, v. 20, p. 135-140, 1996.

9. DEBARBA, L.; AMADO, T. J. C. Desenvolvimento de sistemas de produção e milho no sul do Brasil com características de sustentabilidade. Revista Brasileira de Ciência do Solo, Campinas, v. 21, p. 473-480, 1997.

10. DERPSCH, R.; SIDIRAS, N.; HEINZMANN, F. X. Manejo do solo com coberturas verdes de inverno. Pesquisa Agropecuária Brasileira, Brasília, v. 20, p. 761-773, 1985.

11. EMBRAPA. Caracterização dos solos do município de Castro. Elaborado por: Fasolo, P.J.; Carvalho, A.P.; Pötter, R.O.; Bognola, I.A.; Bhering, S.B.; Martorano, L.G. Rio de Janeiro: Embrapa Solos, 2002. (Boletim de Pesquisa e Desenvolvimento, 09).

12. FONTOURA, S.M.V. Adubação nitrogenada na cultura do milho em Entre Rios, Guarapuava, PR. Guarapuava: Fundação Agrária de Pesquisa Agropecuária, 2005.94 p.

13. HEINRICHS, R.; AITA, C.; AMADO, T. J. C.; FANCELLI, A. L. Cultivo consorciado de aveia e ervilhaca: relação C/N da fitomassa e produtividade do milho em sucessão. Revista Brasileira de Ciência do Solo, Viçosa, v. 25, p. 331-340, 2001.

14. IAPAR. Cartas climáticas do estado do Paraná - 2000. Disponívelem:<http://www.iapar.br/Sma/Cartas_Climaticas>. Acesso em 23 JAN 2005.

15. MONEGAT, C. Plantas de cobertura de solo: características e manejo em pequenas propriedades. Chapecó: Edição do Autor, $1991.337 \mathrm{p}$.

16. PAVINATO, A.; CERETTA, C. A.; BEVILÁQUA, G. P. Resíduos culturais de espécies de inverno e o rendimento de grãos de milho no sistema de cultivo mínimo. Pesquisa Agropecuária Brasileira, Brasília, v. 29, p. 1427-1432, 1994

17. RAIJ, B. van; CANTARELLA, H.; QUAGGIO, J.A.; FURLANI, A.M.C. Recomendações de adubação e calagem para o estado de São Paulo. 2.ed., Campinas: Instituto Agronômico e Fundação IAC, 1996. 285p

18. ROMAN, E. S.; DIDONET, A. D. Controle de plantas daninhas no sistema plantio direto de trigo e soja. Passo Fundo: EMBRAPA-CNPT, 1990. 32 p. (Circular 2).

19. SÁ, J.C.M. Calagem em solos sob plantio direto da região dos Campos Gerais, Centro Sul do Paraná. In: CURSO SOBRE MANEJO DO SOLO NO SISTEMA PLANTIO DIRETO. Anais. Castro: Fundação ABC, 1995a. p. 78-112.

20. SÁ, J.C.M. Nitrogênio: influência da rotação de culturas e resposta da cultura de milho em solos sob plantio direto. In:CURSO SOBRE MANEJO DO SOLO NO SISTEMA PLANTIO DIRETO. Anais. Castro: Fundação ABC, 1995b. p. 213-227.

21. SILVA, J.C.P.M. da. Esterco líquido de gado de leite e adubação mineral influenciando a produção de silagem e propriedades químicas do solo na região dos Campos Gerais do Paraná . Curitiba, 2005. 63 f. Dissertação (Mestrado em Ciência do Solo) - Curso de Pós-Graduação em Agronomia, Setor de Ciências Agrárias, Universidade Federal do Paraná.

22. VALENTINI, M.H.E. Época de manejo químico de coberturas de solo para a cultura do feijoeiro em sistema plantio direto na palha. Curitiba: 1999. 43 f. Dissertação (Mestrado em Agronomia - Produção Vegetal) - Curso de Pós-Graduação em Agronomia, Setor de Ciências Agrárias, Universidade Federal do Paraná.

23. WILDNER, L. P.; DADALTO, G. G. Adubos verdes de inverno para o oeste catarinense. Revista Agropecuária Catarinense, Florianópolis, v. 5, p. 3-6, 1992.

Recebido em 13/06/2005 Aceito em 14/05/2007 